\title{
Localized Cystic Disease of the Kidney in Pediatric Patients: Clinical and Imaging Findings With Long Term Follow Up
}

\author{
Haesung Yoon \\ Severance Hospital \\ Myung-Joon Kim ( $\nabla$ mjkim@yuhs.ac) \\ CHA Ilsan Medical Center \\ Hyun Joo Shin \\ Yongin Severance Hospital \\ Mi-Jung Lee \\ Severance Hospital
}

\section{Research Article}

Keywords: localized cystic disease of the kidney, children, ultrasonography

Posted Date: May 21st, 2021

DOI: https://doi.org/10.21203/rs.3.rs-534087/v1

License: (c) (i) This work is licensed under a Creative Commons Attribution 4.0 International License. Read Full License

Version of Record: A version of this preprint was published at Journal of Pediatric Urology on November 1st, 2021. See the published version at https://doi.org/10.1016/j.jpurol.2021.11.002. 


\section{Abstract}

Background: This study aimed to describe the clinical and imaging findings, including ultrasonography (US) findings, and long-term follow-up results in pediatric patients with localized cystic disease of the kidney (LCDK).

Methods: From January 2002 to August 2020, pediatric patients diagnosed with LCDK based on imaging findings showing multiple localized renal cysts with intervening normal renal parenchyma were retrospectively reviewed. Clinical presentations and US features of the affected and contralateral kidneys were reviewed and compared with computed tomography or magnetic resonance imaging findings, if available.

Results: A total of 18 patients (male:female $=11: 7$; median age, 8 years) were included. Initial clinical presentations were incidental findings $(n=5)$, abdominal pain $(n=5)$, or hematuria $(n=5)$. Of the seven $(7 / 18,39 \%)$ patients who showed multiple hyperechoic foci with ring-down artifacts within the cystic lesions on US, six patients showed focal calcification of the cysts on CT. Two $(2 / 18,11 \%)$ patients had tiny cysts in the contralateral kidney. During follow-up (range, 2-122 months), there was an increase in lesion size, with ipsilateral renal growth in four (4/18, 22\%) patients. There was no renal function impairment at the initial presentation or during follow-up in all patients.

Conclusions: LCDK can present with tiny calcifications (39\%), contralateral tiny renal cysts (11\%), and mild size increase during renal growth (22\%) in children without renal function impairment. Follow-up US is recommended without surgical intervention in these typical cases.

\section{Background}

Cystic disease of the kidney in the pediatric population is relatively rare and has a wide range of differential diagnoses. Localized cystic disease of the kidney (LCDK) is an uncommon, non-familial, and non-progressive kidney disorder that is not associated with cysts or malformations in other organs. It involves a part of the kidney (or rarely the entire kidney) with multiple cysts surrounded by normal renal parenchyma[1-3]. It is usually diagnosed in adults[2-4]. The differentiation of LCDK from other renal cystic diseases is important because LCDK is a benign condition and usually does not require any specific management or surgical intervention[5]. Therefore, it is important to easily and accurately diagnose LCDK and differentiate it from other cystic renal diseases.

The typical imaging finding of LCDK is a cluster of tightly spaced cysts of variable size within a single kidney with normal intervening parenchyma. Some cysts show internal calcification, and tiny one or two simple cysts are occasionally seen in the contralateral kidney[2-4]. These findings are based on computed tomography (CT) features in the adult population.

There have been only 11 previously reported pediatric LCDK cases[5-13]. Since LCDK in the pediatric population is rare, more than $50 \%$ of these reported cases were misdiagnosed and underwent unnecessary surgical excision. Therefore, this study aimed to review ultrasonography (US) findings and longer-term follow-up results in pediatric patients with LCDK.

\section{Methods}

Our Institutional Review Board approved this study and waived the requirement for informed consent because of the retrospective nature of the study. From January 2002 to October 2020, we retrospectively reviewed patients who were under the age of 18 who had the following imaging findings indicative of LCDK-cluster of tightly spaced cysts of variable size within a single kidney, but otherwise normal renal parenchyma between the cyst and throughout the rest of the kidney[1-3,11]. We excluded patients who showed a capsule around the cysts to differentiate cystic neoplasms[2]. In addition, we excluded patients with multiple cysts in the ipsilateral and contralateral kidneys or cysts in other organs such as the pancreas or the liver to exclude polycystic kidney disease[11]. US features of the affected and contralateral kidneys were reviewed and compared with computed tomography (CT) or magnetic resonance imaging (MRI) findings, if available in the medical records. The medical records of the patients were reviewed to evaluate data on age at presentation, sex, presence or absence of family history of renal disease, presenting symptoms, follow-up duration, presence of renal function abnormality based on blood urea nitrogen and blood creatinine levels, and types of intervention performed.

\section{Results}

\section{Clinical features}

In total, 18 patients were diagnosed with LCDK during the study period. Eleven patients were male, and seven patients were female, with an age range of 3-16 years (median, 8 years). The most common presentations were non-specific abdominal pain $(n=5)$, gross or microscopic hematuria $(n=5)$, or incidental lesion $(n=5)$. Urinary tract infection $(n=1)$, fever $(n=1)$, or nausea $(n=1)$ were less common presentations. None of the patients had a family history of renal disease.

Based on imaging findings, conservative management with follow-up was performed in most cases, except in one patient who underwent partial nephrectomy for a suspected renal tumor. The follow-up duration was 2-122 months (median, 37.5 months). No renal complication or renal 
function impairment was identified in any patient during follow-up.

\section{Radiological Findings}

US was performed in all patients. CT findings were available in nine patients, and MRI findings were available in six patients. Eleven patients had LCDK in the right kidney, and seven patients had LCDK in the left kidney. LCDK had no significant location predilection (Table 1). In all patients, US findings were characterized by multiple variable-sized, conglomerated, round cystic lesions with intervening normal renal parenchyma without a definite capsule and preserved cortical rim. The lesions showed no predisposition to the renal cortex or the renal medulla. Each cyst was round or oval with variable size. The cysts were relatively well defined by thin walls and had a sharp interface with the adjacent renal parenchyma, as previously described[2,3].

Table 1

Summary of clinical and radiologic features.

\begin{tabular}{|c|c|c|c|c|c|c|c|c|c|c|}
\hline $\begin{array}{l}\text { Patient } \\
\text { no. }\end{array}$ & $\begin{array}{l}\text { Age at } \\
\text { presentation }\end{array}$ & Sex & $\begin{array}{l}\text { Presenting } \\
\text { symptoms }\end{array}$ & $\begin{array}{l}\text { Types of } \\
\text { management }\end{array}$ & $\begin{array}{l}\text { Follow- } \\
\text { up } \\
\text { (month) }\end{array}$ & $\begin{array}{l}\text { Family } \\
\text { history }\end{array}$ & Laterality & Location & $\begin{array}{l}\text { Hyperechoic } \\
\text { foci on US }\end{array}$ & $\begin{array}{l}\text { Cyst in } \\
\text { contralateral } \\
\text { kidney }\end{array}$ \\
\hline 1 & 4 months & $\mathrm{M}$ & Fever & Conservative & 35 & No & Left & Lower & - & - \\
\hline 2 & 10 years & $\mathrm{F}$ & $\begin{array}{l}\text { Abdominal } \\
\text { pain }\end{array}$ & Conservative & 98 & No & Right & Upper & + & - \\
\hline 3 & 8 years & M & Hematuria & Conservative & 30 & No & Left & $\begin{array}{l}\text { Upper, } \\
\text { mid }\end{array}$ & + & - \\
\hline 4 & 5 months & $\mathrm{F}$ & $\begin{array}{l}\text { Abdominal } \\
\text { pain }\end{array}$ & Conservative & 56 & No & Right & $\begin{array}{l}\text { Upper, } \\
\text { lower }\end{array}$ & - & + \\
\hline 5 & 3 months & $\mathrm{F}$ & Incidental & Conservative & 122 & No & Right & Upper & + & + \\
\hline 6 & 3 months & $\mathrm{M}$ & $\begin{array}{l}\text { Urinary tract } \\
\text { infection }\end{array}$ & Conservative & 43 & No & Right & $\begin{array}{l}\text { Upper, } \\
\text { lower }\end{array}$ & - & - \\
\hline 7 & 10 years & $\mathrm{F}$ & Incidental & Conservative & 43 & No & Right & Mid & + & - \\
\hline 8 & 14 years & $\mathrm{F}$ & $\begin{array}{l}\text { Microscopic } \\
\text { hematuria }\end{array}$ & Conservative & 72 & No & Right & Mid & - & - \\
\hline 9 & 14 years & M & $\begin{array}{l}\text { Gross } \\
\text { hematuria }\end{array}$ & Nephrectomy & 0 & No & Right & Mid & + & - \\
\hline 10 & 7 months & $\mathrm{M}$ & Incidental & Conservative & 40 & No & Left & Mid & - & - \\
\hline 11 & 9 years & $M$ & Hematuria & Conservative & 3 & No & Left & Mid & - & - \\
\hline 12 & 8 years & M & Hematuria & Conservative & 56 & No & Right & Upper & - & - \\
\hline 13 & 14 years & $\mathrm{F}$ & Incidental & Conservative & 40 & No & Right & Lower & - & - \\
\hline 14 & 8 years & $M$ & Nausea & Conservative & 32 & No & Left & Upper & - & - \\
\hline 15 & 5 months & $\mathrm{F}$ & Incidental & Conservative & 6 & No & Left & $\begin{array}{l}\text { Mid } \\
\text { lower }\end{array}$ & - & - \\
\hline 16 & 6 years & $\mathrm{M}$ & $\begin{array}{l}\text { Abdominal } \\
\text { pain }\end{array}$ & Conservative & 15 & No & Right & Mid & + & - \\
\hline 17 & 16 years & M & $\begin{array}{l}\text { Abdominal } \\
\text { pain }\end{array}$ & Conservative & 17 & Unknown & Left & Mid & - & - \\
\hline 18 & 9 years & M & $\begin{array}{l}\text { Abdominal } \\
\text { pain }\end{array}$ & Conservative & 2 & No & Right & $\begin{array}{l}\text { Mid } \\
\text { lower }\end{array}$ & + & - \\
\hline
\end{tabular}

Seven $(7 / 18,39 \%)$ patients showed multiple hyperechoic foci with ring-down artifacts within the normal intervening parenchyma at the cystic lesion on US (Fig. 1), including one patient who developed hyperechoic foci during follow-up (Fig. 2). Of these seven patients, six patients showed focal calcifications within the cyst walls on CT. There were no definite hyperattenuating cysts on precontrast CT. Two $(2 / 18,11 \%)$ patients had a tiny single cortical cyst in the contralateral kidney. No cystic lesions with intense wall enhancement or mural nodules were identified on either CT or MRI.

During follow-up, the cystic lesion size increased in four (4/18, 22\%) patients. The initial age at diagnosis in these four patients was $3,4,5$ months and 8 years. The absolute lesion length had increased with a range of 6-20 mm during follow-up (35-122 months). However, it was not significant 
when the ipsilateral renal growth (range 7-30 mm) was considered.

\section{Pathology}

For the patient who underwent partial nephrectomy for suspected renal neoplasm (Fig. 3), pathological findings were evaluated. On cross-section, the lesion revealed multilocular cysts of variable size lined by flattened epithelium. The cysts contained clear serous fluid with smooth walls and no evidence of tumor or papillary formation. There was intervening normal renal parenchyma in the septum.

\section{Discussion}

LCDK was first described in 1979 by Cho et al.[6] and the terminology was defined by Slywotzkey et al.[2]. Since then, many studies have documented this unique disease, mostly in the adult population. Only 11 pediatric cases have been documented thus far (Supplementary Table 1) [5-13]. Seven patients were male and four patients were female, with their age ranging from 1.5 months to 16 years. Due to the rarity of the disease, LCDK was not included in the international working group consensus statement for kidney cysts and cystic kidney disease in children[14].

In our study, LCDK was present in 18 pediatric patients with a mean age of 8 years (range, 3 months to 16 years). Six patients were diagnosed with LCDK less than one year of age. One patient underwent nephrectomy, and 17 patients were conservatively treated by US follow-up. This is the first study to report multiple cases of pediatric LCDK with long-term US follow-up. Lack of awareness of the disease may lead to misdiagnosis and mistreatment, including unnecessary nephrectomy, as in previously reported pediatric cases[5-13]. Of the 11 pediatric reported cases, seven cases underwent surgical excision[5, 6, 8, 10, 12, 13, 15]. Among these seven cases, one patient underwent preoperative chemotherapy before nephrectomy because the radiologist suspected a malignant lesion[13]. Four cases were managed conservatively, and follow-up data were available in two cases. One case showed no interval change after seven years[7] and after one year[9].

In our study, LCDK was incidentally found in $27.8 \%$ patients. Sixty percent of the patients who were incidentally diagnosed with LCDK were under the age of one year. Our cases and previously reported cases that were diagnosed in newborns and during infancy suggest that LCDK may develop during the pediatric period and could be found incidentally during adulthood. The incidental initial diagnosis in adulthood might be possible because LCDK is non-progressive and there is no loss of renal function in the involved patients[2, 3].

The most common modality used in the evaluation of LCDK has been CT, and the disease has characteristic findings: multiple conglomerated simple cysts with normal intervening renal parenchyma[2, 3, 11]. US have also typically been used as the primary imaging tool in previous reports but the role has been underestimated. This might be because most previous studies have been in the adult population. In our study, similar characteristic findings of LCDK were also seen on US. Moreover, seven (38.8\%) patients showed multiple hyperechoic foci with ring-down artifacts at intervening normal parenchyma within the cystic lesions on US. Six of seven patients showed focal calcification within the cyst walls on the corresponding CT. One patient developed hyperechoic foci during follow-up; however, the corresponding CT was not available in this patient. This finding is consistent with that of previous studies in the adult population, which demonstrated scattered calcification in cyst walls in $22-42 \%$ of the reported LCDK cases on CT[2,3]. This is a discriminating point from other cystic masses, such as multilocular cystic nephroma, since calcification is rare[16]. The hyperechoic foci observed on US are similar to the previously noted lesions in autosomal recessive polycystic kidney disease (ARPKD)[17]. Urine stagnation in dilated tubules, which is a consequence of calcium precipitation, decreases excretion of urinary citrate, and alkaline urine has been suggested to be a possible mechanism for calcification in patients with ARPKD[18]. However, there is a lack of evidence on the pathological correlation to confirm these findings in LCDK, but the appearance and ring-down artifacts suggest the precipitation of some crystalline material, perhaps calcium compounds, in the normal intervening renal parenchyma. Ding et al. pathologically confirmed that cystic septa contain tubules and glomeruli and that the cystic spaces of LCDK were continuous with the dilated collecting ducts in some cases. Lymphocyte infiltrates, foamy histiocyte aggregates, and refractile crystals were occasionally identified in the cystic spaces of LCDK[1].

LCDK may resemble autosomal dominant polycystic kidney disease (ADPKD), but there are important points of discrimination. LCDK is unilateral and almost always involves only a part of the affected kidney, and coexistence of cystic lesions in other organs such as the liver or pancreas is uncommon[1-3,11]. ADPKD can affect one kidney before contralateral renal cysts are visualized on imaging studies, mimicking unilateral renal involvement, especially in younger patients[19]. Since the gene for ADPKD has been identified in more than $90 \%$ of the patients, genetic evaluation is useful for differential diagnosis[20,21]. However, in our study, genetic evaluation was not performed in all patients. Two patients showed tiny, simple cysts in the contralateral kidney. There were no cysts in other organs in these patients. Simple cysts in the contralateral kidney have also been reported in the LCDK patients in adult population[2, 3, 22]. In our study, there were six patients who were under one year who had characteristic US findings of LCDK. There may be concerns about the early manifestation of ADPKD in these infant patients. However, only one patient developed a tiny simple cyst in the contralateral kidney during follow-up. Imaging of the family members in the aforementioned patient did not reveal any cysts in the major organs. Renal function was within the normal range during the 56-month follow-up in this patient.

Previously reported LCDK studies have focused on CT and MRI findings because most of the case studies included adult patients. Establishing US findings of LCDK are very important in the pediatric population since US is a radiation- and sedation-free tool that can be easily be used for diagnosis and follow-up examination. From our experience, LCDK is a very stable and benign disease entity, but it requires follow-up imaging to 
monitor potential interval size changes, as four patients in our study had an interval size increase during follow-up. However, considering the interval growth increase of the normal kidney during pediatric development, the finding was not significant. Establishing US findings of LCDK may help reduce unnecessary additional CT and MRI in pediatric patients. If cystic lesions with typical features of LCDK are noted on US, follow-up US is recommended in the pediatric population.

This study has some limitations. First, the study included a small number of patients and there was only one pathologically proven case. Second, we did not perform genetic studies related to renal cystic disease in all patients. Imaging of family members was performed in only one patient. However, there was no renal insufficiency or cyst in other organs in any patients. Third, since the follow-up duration was relatively long, hyperechoic foci in LCDK might have been more conspicuous due to technological improvement. However, this report describes a noteworthy number of pediatric LCDK cases, and long-term patient follow-up by imaging enhances the clinical significance of this study.

\section{Conclusions}

LCDK can be diagnosed when multifocal conglomerated cystic lesions with intervening normal renal parenchyma in one kidney are identified on US. LCDK can present with tiny calcifications (39\%), contralateral tiny renal cysts (11\%), and mild size increase during renal growth (22\%) in children without renal function impairment. Follow-up US is recommended without surgical intervention in these typical cases.

\section{Declarations}

Ethics approval and consent to participate

- Following the Declaration of Helsinki, the study was approved as a retrospective human study by the Institutional Review Board of Severance Hospital (4-2019-0522). The informed consent of patient, parents, or guardians was waived. All methods were carried out in accordance with relevant guidelines and regulations.

Consent for publication : not applicable

Availability of data and materials

- All data generated or analysed during this study are included in this published article and its supplementary information files

Competing interests: The authors have no competing interest to declare.

Funding: not applicable

Authors' contributions:

HY, MJK: study concept and design, data acquisition, data analysis and interpretation, and writing of manuscript. HY, MJK, HJS, MJL: data analysis, interpretation and revision of manuscript for important intellectual content. All authors read and approved the final manuscript.

Acknowledgements: not applicable

\section{References}

1. Ding Y, Chen L, Deng FM, Melamed J, Fan R, Bonsib S, Zhou M: Localized cystic disease of the kidney: distinction from cystic neoplasms and hereditary polycystic diseases. Am J Surg Pathol 2013, 37(4):506-513.

2. Slywotzky CM, Bosniak MA: Localized cystic disease of the kidney. AJR Am J Roentgenol 2001, 176(4):843-849.

3. Kim DJ, Kim MJ: Localized cystic disease of the kidney: CT findings. Abdom Imaging 2003, 28(4):588-592.

4. Dario Casas J, Mariscal A, Perez-Andres R: Localized renal cystic disease: imaging findings, pathologic correlation, and management approach. Computerized medical imaging and graphics : the official journal of the Computerized Medical Imaging Society 2002, 26(4):247-249.

5. Boybeyi O, Karnak I, Orhan D, Ciftci AO, Tanyel FC, Kale G, Senocak ME: Cystic nephroma and localized renal cystic disease in children: diagnostic clues and management. Journal of pediatric surgery 2008, 43(11):1985-1989.

6. Cho KJ, Thornbury JR, Bernstein J, Heidelberger KP, Walter JF: Localized cystic disease of the kidney: angiographic-pathologic correlation. AJR Am J Roentgenol 1979, 132(6):891-895.

7. Levine E, Huntrakoon M: Unilateral renal cystic disease: CT findings. Journal of computer assisted tomography 1989, 13(2):273-276.

8. Middlebrook PF, Nizalik E, Schillinger JF: Unilateral renal cystic disease: a case presentation. J Uro/ 1992, 148(4):1221-1223.

9. Dugougeat F, Navarro O, Soares Souza AS, Geary D, Daneman A: Multiple unilateral renal cysts in two children. Pediatric radiology 2000, 30(5):346-348. 
10. Taskinen S, Lohi J, Kivisaari R, Fagerholm R, Rintala R, Taskinen M: Segmental cystic kidney tumours in children. Scandinavian journal of urology and nephrology 2009, 43(6):476-481.

11. Neyaz Z, Kumar S, Lal H, Kapoor R: Localized cystic disease of the kidney: a rare entity. J Radiol Case Rep 2012, 6(7):29-35.

12. Solak A, Gur MS, Genc B, Sahin N: Localized cystic disease of the kidney: a rare cause of hypertension in a young adult. J Clin Imaging Sci 2013, 3:33.

13. Kaselas C, Demiri C, Mouravas V, Koutra E, Anastasiadis K, Spyridakis I: Is it always Wilms' tumor? Localized cystic disease of the kidney in an infant: An extremely rare case report and review of the literature. Pediatric reports 2020, 12(2):8483.

14. Gimpel C, Avni EF, Breysem L, Burgmaier K, Caroli A, Cetiner M, Haffner D, Hartung EA, Franke D, König J et al: Imaging of Kidney Cysts and Cystic Kidney Diseases in Children: An International Working Group Consensus Statement. Radiology 2019, 290(3):769-782.

15. Behr CA, Hesketh AJ, Williamson AK, Soffer SZ, Glick RD: Localized cystic disease of the kidney: A rare diagnosis of this uncommon condition in a child. Journal of Pediatric Surgery Case Reports 2016, 12:41-43.

16. Agrons GA, Wagner BJ, Davidson AJ, Suarez ES: Multilocular cystic renal tumor in children: radiologic-pathologic correlation. Radiographics 1995, 15(3):653-669.

17. Traubici J, Daneman A: High-Resolution Renal Sonography in Children with Autosomal Recessive Polycystic Kidney Disease. American Journal of Roentgenology 2005, 184(5):1630-1633.

18. Lucaya J, Enriquez G, Nieto J, Callis L, Garcia Pena P, Dominguez C: Renal calcifications in patients with autosomal recessive polycystic kidney disease: prevalence and cause. AJR Am J Roentgenol 1993, 160(2):359-362.

19. Porch P, Noe HN, Stapleton FB: Unilateral presentation of adult-type polycystic kidney disease in children. J Uro/ 1986, 135(4):744-746.

20. Kimberling WJ, Kumar S, Gabow PA, Kenyon JB, Connolly CJ, Somlo S: Autosomal dominant polycystic kidney disease: localization of the second gene to chromosome 4q13-q23. Genomics 1993, 18(3):467-472.

21. Reeders ST, Breuning MH, Corney G, Jeremiah SJ, Meera Khan P, Davies KE, Hopkinson DA, Pearson PL, Weatherall DJ: Two genetic markers closely linked to adult polycystic kidney disease on chromosome 16. Br Med J (Clin Res Ed) 1986, 292(6524):851-853.

22. Dowden EE, Osunkoya AO, Baumgarten DA: Localized cystic disease of the kidney: an unusual entity that can mimic a cystic neoplasm. Am J Kidney Dis 2010, 55(3):609-613.

\section{Figures}




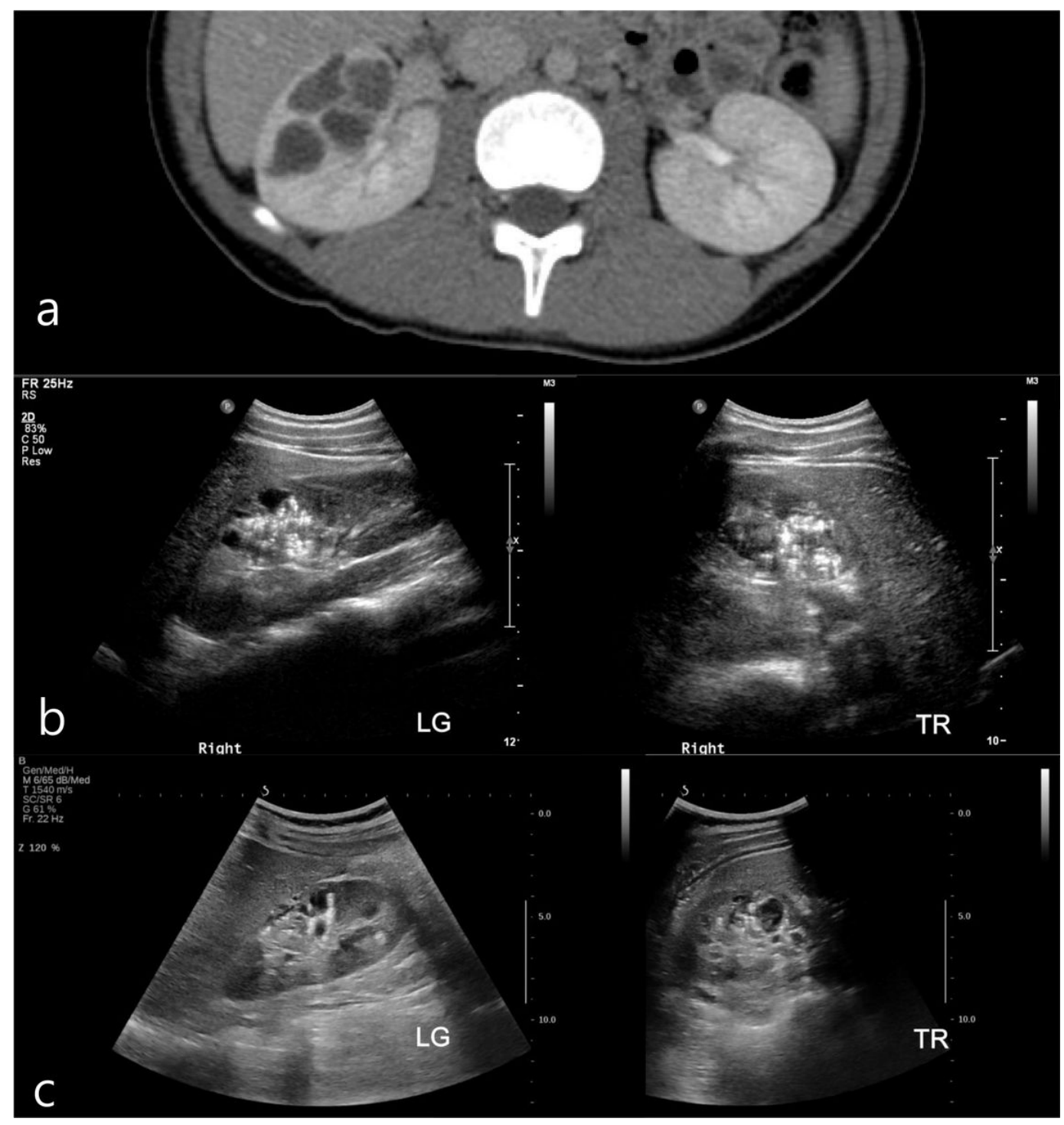

\section{Figure 1}

An 11-year-old boy who presented with abdominal pain and was incidentally diagnosed with localized cystic disease of the kidney (LCDK). A. Axial contrast-enhanced computed tomography scan showing the corresponding cystic lesion with multiple variable-sized conglomerating cysts at the upper portion of the right kidney. B. Follow-up ultrasonography (US) image showing a complex cystic lesion with multiple variable-sized cysts congregated at the upper portion of the right kidney with hyperechoic foci with ring-down artifacts within the cystic lesions. LG (long), TR (transverse). C. There was no interval change in the LCDK in the right kidney for 98 months. 


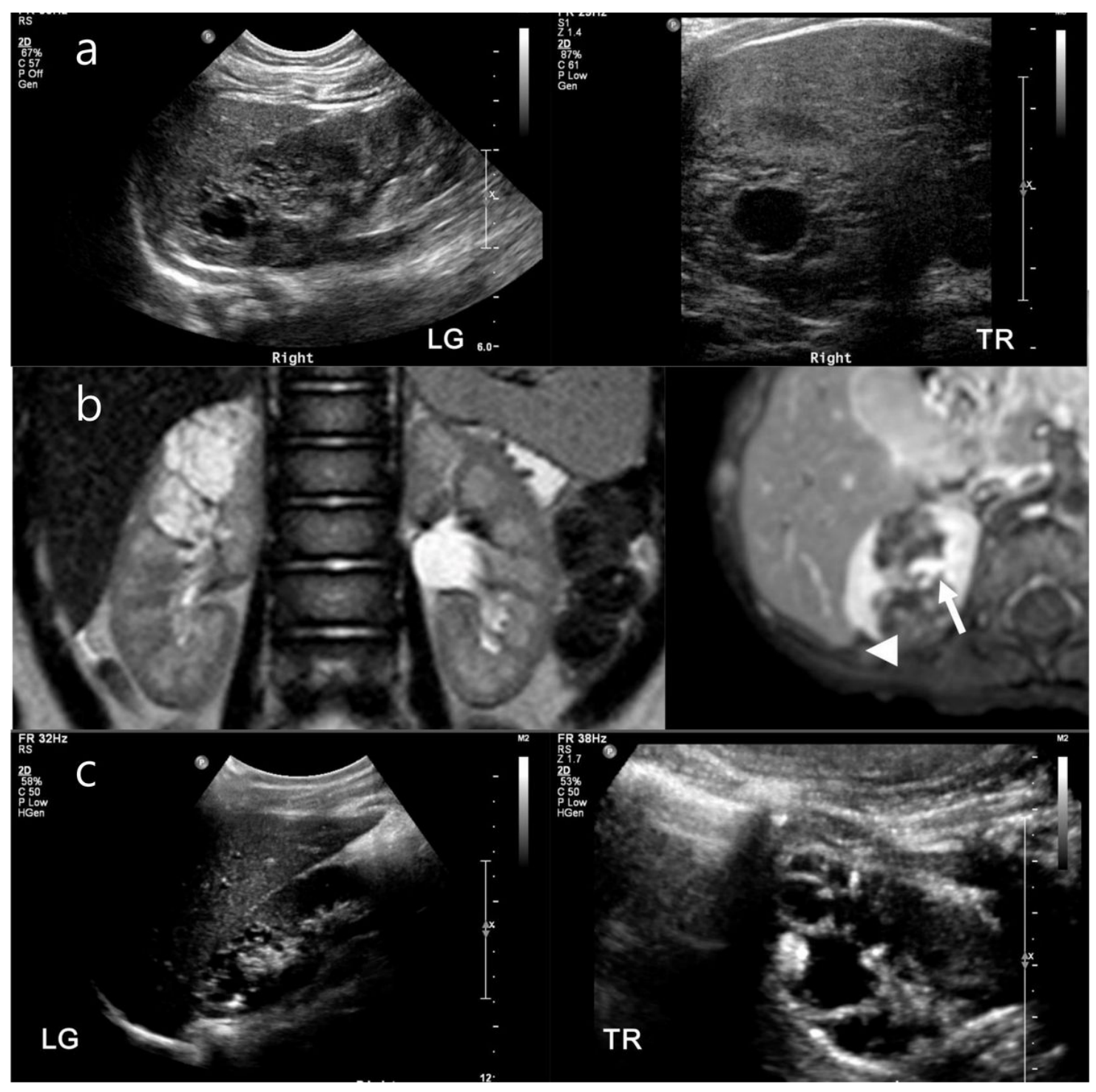

\section{Figure 2}

A 3-month-old boy who was asymptomatic and diagnosed with localized cystic disease of the kidney. A. Initial ultrasonography (US) image showing a complex cystic lesion with multiple variable-sized cysts congregated at the upper pole of the right kidney with a longitudinal extent of approximately $2.6 \mathrm{~cm}$. The longitudinal length of the right kidney was $6.6 \mathrm{~cm}$. LG (long), TR (transverse). B. During the 9-month follow-up, single shot spin echo magnetic resonance imaging showing the same lesion in the right kidney without interval size change. The left kidney is normal in appearance. Axial post contrast T1-weighted 3D gradient-echo images showing intervening normal enhancing renal parenchyma within the cystic lesion (arrowhead), with normal contrast excretion in the delayed phase (arrow). C. At the age of 10 years, follow-up US showing newly developed multiple hyperechoic foci with ring-down artifacts at normal intervening parenchyma within the cystic lesions. The cystic lesion shows mildly increased size, measuring $3.6 \mathrm{~cm}$. The longitudinal length of the right kidney was $9.9 \mathrm{~cm}$. 


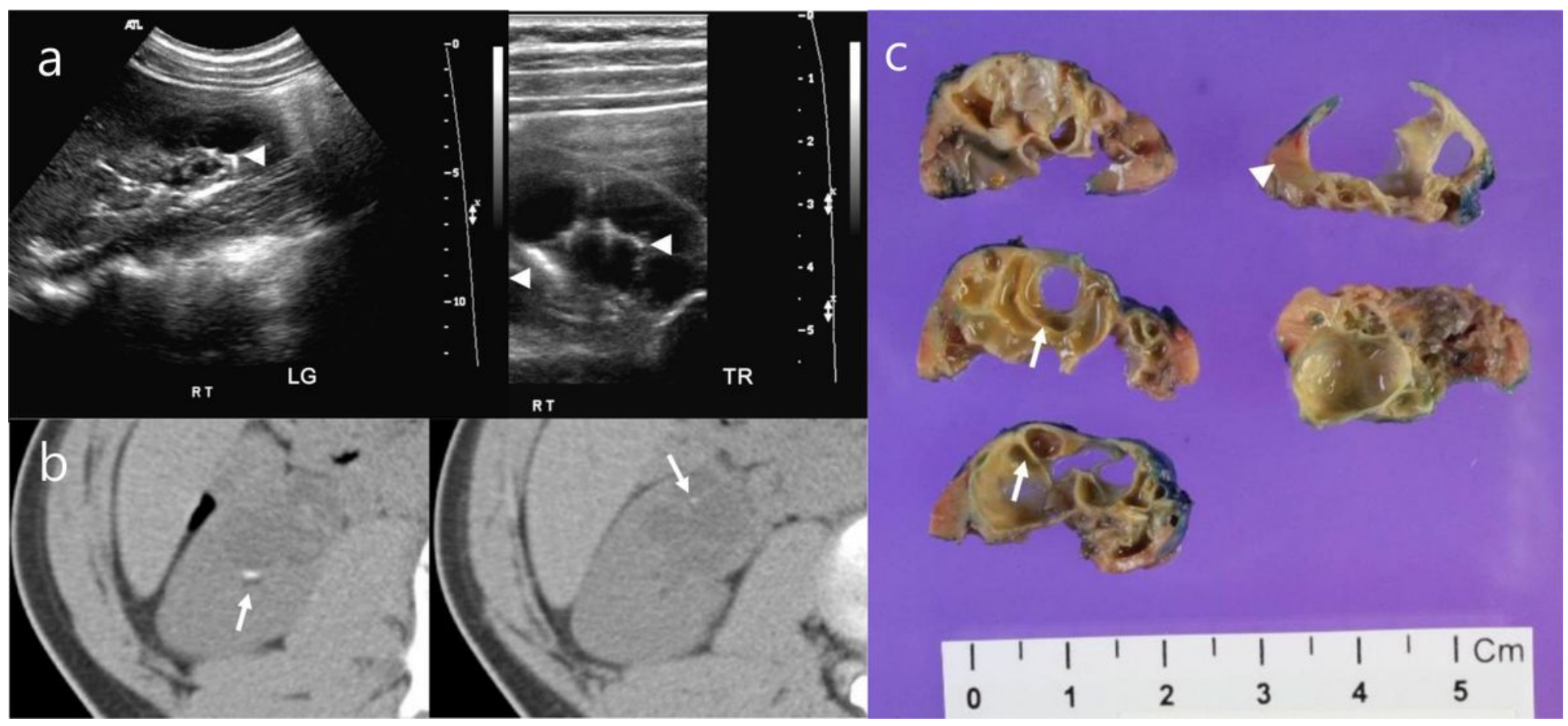

Figure 3

A 14-year-old boy who presented with gross hematuria was diagnosed with localized cystic disease of the kidney by partial nephrectomy. A. Initial US image shows multiple variable-sized, conglomerated, round cystic lesions involving the lower pole of the right kidney, measuring approximately $2.5 \mathrm{~cm}$. There are multiple hyperechoic foci with ring-down artifacts at normal intervening parenchyma within the cystic lesions on US (arrowhead). B. Pre-contrast computed tomography scan shows corresponding calcifications within the septa of the cystic lesion (arrows). C. Pathological crosssectional specimens show multilocular cysts localized in one area with normal intervening renal parenchyma (arrows) and no evidence of capsule or dysgenic elements. Uninvolved areas were normal (arrow head).

\section{Supplementary Files}

This is a list of supplementary files associated with this preprint. Click to download.

- SupplementaryMaterial120210318.docx 